This manuscript has been accepted for publication in Attention, Perception \& Psychophysics

\title{
The development of foraging organization
}

Authors: Inga María Ólafsdóttir ${ }^{1, \dagger} ;$ Steinunn Gestsdóttir ${ }^{1} ;$ \& Árni Kristjánsson ${ }^{1,2}$.

${ }^{1}$ Department of Psychology, School of Health Sciences, University of Iceland.

${ }^{2}$ School of Psychology, National Research University Higher School of Economics, Russian Federation.

†Corresponding author: Inga María Ólafsdóttir, Department of Psychology, School of Health Sciences, University of Iceland, 101 Reykjavík, Iceland. E-mail: $\underline{\text { imo4@ hi.is }}$ 


\begin{abstract}
In foraging tasks multiple targets must be found within a single display. The targets can be of one or more types, typically surrounded by numerous distractors. Visual attention has traditionally been studied with single target search tasks but adding more targets to the search display results in several additional measures of interest, such as how attention is oriented to different features and locations over time. We measured foraging among five age groups: Children in grades $1,4,7$, and 10, as well as adults, using both simple feature foraging tasks and more challenging conjunction foraging tasks, with two target types per task. We assessed participants' foraging organization, or systematicity when selecting all the targets within the foraging display, on four measures: Intertarget distance, number of intersections, best-r, and the percentage above optimal path length (PAO). We found that foraging organization increases with age, in both simple feature-based foraging and more complex foraging for targets defined by feature conjunctions, and that feature foraging was more organized than conjunction foraging. Separate analyses for different target types indicated that children's, and to some extent adults', conjunction foraging consisted of two relatively organized foraging paths through the display where one target type is exhaustively selected before the other target type is selected. Lastly, we found that the development of foraging organization is closely related to the development of other foraging measures. Our results suggest that measuring foraging organization is a promising avenue for further research into the development of visual orienting.
\end{abstract}


Picture a child eating a sugary cereal filled with marshmallows. Instead of eating it by the spoonful, the child sifts through the bowl, picking out the marshmallows from the cereal. This is an example of a foraging task. Foraging tasks involve visual search where multiple targets must be found within a single display. The targets can be of one or more types and are usually surrounded by numerous distractors of one or more types. While visual attention has traditionally been studied with single target search tasks (see e.g. Huang \& Pashler, 2005; Maljkovic \& Nakayama, 1994, 1996; Najemnic \& Geisler, 2005; Pashler, 1987; Wolfe, 2010; see Kristjánsson, 2015 for a critical review) foraging studies have been gaining more interest in the last decade as they may provide a more intricate picture of how we orient in the visual world (see e.g. Cain, Vul, Clark, \& Mitroff, 2012; Kristjánsson, Jóhannesson, \& Thornton, 2014; Ólafsdóttir, Gestsdóttir, \& Kristjánsson, 2019, 2020; Thornton, de’Sperati \& Kristjánsson, 2019; Wolfe, 2013; Wolfe, Cain, \& Aizenman, 2019; Zhang, Gong, Fougnie, \& Wolfe, 2017; see Kristjánsson, Ólafsdóttir \& Kristjánsson, 2019 for review). These studies have revealed that when observers forage for targets of different types, the conspicuousness of the search item is crucial. If the items are clearly visible and easily discerned from the distractors, subjects tend to readily switch between target categories as they forage. On the other hand, if the target items are indistinct, or very similar to the distractors, observers tend to select the same target type in long runs, without switching (Bond, 1982; Dukas \& Ellner, 1993).

\section{The Development of Visual Attention and Single Target Search Tasks}

Foraging research is a relatively recent development in studies of human visual attention, and what is known about its development has mostly come from studies using single target search tasks. A large body of literature has revolved around performance differences between feature and conjunction search (see e.g. Humphrey \& Kramer, 1997; Scialfa \& Joffe, 1998; Treisman, Sykes \& Gelade, 1977; see Kristjánsson \& Egeth, 2020 for 
review). When targets are defined by a single feature, such as color or shape, search is usually quick and effortless, regardless of the number of distractor items on the screen. However, when targets are defined by a conjunction of two or more features, such as color and shape, e.g., when observers search for a blue triangle amongst blue dots and yellow triangles, search times increase proportionately with the number of distractor items (Humphrey \& Kramer, 1997; Scialfa \& Joffe, 1998; Treisman et al., 1977). Studies on children‘s visual search abilities have suggested that children and infants ${ }^{6}$ feature search is efficient and accurate (Adler \& Orprecio, 2006; Gerhardstein \& Rovee-Collier, 2002; Sireteanu \& Rieth, 1992). If the target item is defined by a conjunction of two or more features, however, children have great difficulty completing the task, evident from high error rates (Gerhardstein \& RoveeCollier, 2002; Lobaugh, Cole, \& Rovet, 1998) and search times that increase proportionately much more than for adults as distractor number rises (Gerhardstein \& Rovee-Collier, 2002; Merrill \& Lookadoo, 2004; Thompson \& Massaro, 1989; Trick \& Enns, 1998). These results have sparked proposals that different mechanisms underlie processing during feature and conjunction-based searches. By many accounts, mechanisms for processing items that are defined by a single feature, and therefore "pop-out" among distractors, are believed to be innate or develop within the first months of life, whereas more difficult conjunction search depends upon more complex cognitive mechanisms related to the prefrontal cortex, such as executive functions that develop later in life (Gerhardstein \& Rovee-Collier, 2002; Merrill \& Lookadoo, 2004; see Pelegrina et al., 2020 for some relevant evidence regarding ERP's).

\section{Visual Foraging}

Kristjánsson and colleagues (2014) developed a foraging task for touch screen devices, where participants are asked to find and tap on multiple target items among multiple distractors. They speculated whether run number might be manipulated with attentional load, rather than simply by the conspicuousness of items. A run is defined as the consecutive 
selection of the same target type. If an observer switches often between target types, a trial is completed in a series of multiple short runs. If the observer refrains from switching for extended periods, a trial will be completed in few long runs (see overview in Kristjánsson et al., 2019).

To manipulate attentional load, Kristjánsson et al. (2014) made two versions of the task. In the feature foraging version, the targets were distinguishable from the distractors by color. In the conjunction foraging version, the targets differed from the distractors by a colorshape combination and could be red squares and green dots while the distractors were green squares and red dots, or vice versa. They administered those two versions of the foraging task to 16 participants and found that just as when targets are easily distinguishable, people frequently switch between target types during feature foraging. In contrast, most participants completed the conjunction foraging trials in two long runs, exhaustively foraging for one target type before switching to the other. Run behavior was therefore dependent upon attentional load, and not solely the conspicuity of the targets.

\section{Foraging and Development}

Ólafsdóttir et al. $(2016,2019,2020)$ administered the feature and conjunction foraging tasks to children between the ages of 4 to 15 years and compared their performance to that of adults. They found that young children are more error prone and slower foragers than older children and adults, not only during conjunction foraging, but also during feature foraging. Children appeared to reach adult levels of performance around the age of 11 or 12 years. Younger children also tended to complete feature foraging trials in fewer runs than adults, and exhibit switch costs, their target selections were slowed when they switched between target types compared to when they selected the same type of target as during the last selection. A decrease in the number of runs and higher switch costs were seen in the conjunction foraging of all ages but were very small or absent in the feature foraging of older children and adults. 
These results suggested that the ability to detect items defined by a single feature is not as fully developed in childhood as previously posited.

Our previous studies focused on the development of target switching and foraging speed, where most measures were summarized across trials. In the current study, we aim to build upon and expand previous results by looking at foraging patterns within each foraging trial in more depth. We therefore focus on the foraging path through each trial and whether foraging organization changes through development.

\section{Organization}

When more than one target is selected on each trial, several performance measures are available that are not available in single-target search tasks, such as how attention is oriented throughout the display, and how observers process and engage with more than one target type at a time. Cancellation tasks have a lot in common with foraging tasks and could even be defined as such. Subjects are asked to find and mark, or "cancel", multiple targets on a piece of paper (Woods et al., 2013) or a computer screen (Dalmaijer, Van der Stigchel, Nijboer, Cornelissen, \& Husain, 2015). Cancellation tasks have been extensively used in patient groups, for example to measure hemi-spatial neglect in stroke patients (Appelros, Karlsson, Seiger, \& Nydevik, 2002; Buxbaum et al., 2004; Nijboer, Kollen, \& Kwakkel, 2013; Sævarsson, Jóelsdóttir, Hjaltason \& Kristjánsson, 2008; Ten Brink, Visser-Meily, \& Nijboer, 2018), dementia (Fabrigoule et al., 1998; Gainotti, Marra, \& Villa, 2001), and short-term memory deficits (Dalmaijer et al., 2018; Husain \& Rorden). Because of their diagnostic use, it is important to have normative data for cancellation tasks. Therefore, cancellation tasks have also been used in studies with healthy adults of different backgrounds. Some studies show no differences in cancellation performance between different age groups (Benjamins, Dalmaijer, Ten Brink, Nijboer \& Van der Stigchel, 2019; Brucki \& Nitrini, 2008; Saykin et al., 1995; Warren, Moore, \& Voglte, 2008), while others have found a weak age effect (Byrd, Touradji, 
Tang, \& Manly, 2004; Lowery, Ragland, Gur, Gur, \& Moberg, 2004). Other demographic factors, such as sex, ethnicity, and education level, do not seem to affect cancellation behavior (Benjamins et al., 2019).

Although age does not seem to have a large effect on cancellation task performance in adults, visuospatial abilities do increase from childhood into adolescence, and seem to influence visual search performance, both in terms of speed (Burggraaf, van der Geest, Hooge, \& Frens, 2019) and accuracy (Woods et al., 2013). Woods et al. (2013) studied the search organization of children aged 2 to 18 years, with a paper and pencil cancellation task, where 16 target items were dispersed amongst 32 distractors. They kept track of the order of target cancellations to assess how organized the children's search was. Three measures were used to estimate search organization; mean inter-target distance, the number of intersections in the search path, and the best-r. Highly organized multiple-target foraging often involves participants going through the display in columns or rows, systematically from for example left to right, or top to bottom. To capture this movement pattern, Woods et al. (2013) ran a linear regression on first the x-coordinates of the target items and the order in which they were selected, and then did the same for the y-coordinates, to get the Pearson correlation coefficient (r) from both regressions. They then selected the higher coefficient, the best-r, to represent the level of systematicity of each trial. A high Pearson correlation coefficient of the $\mathrm{x}$-coordinates and selection number would mean that the subject systematically moved from left to right, or right to left, whereas a high Pearson correlation coefficient of the ycoordinates would mean a systematic cancelling pattern in rows from top to bottom, or bottom to top. They found that as the children grew older, the mean inter-target distance shortened, the number of intersections went down, and the best-r became higher. Additionally, they found that best-r was connected with the number of errors in a conjunction search task, but no connection was found with feature search. 
Another way of operationalizing foraging organization involves the so-called travelling salesman problem (TSP) where the optimal path through the display, in other words the shortest possible path through every single target item, is calculated. It is then possible to measure whether, and by how much, participants surpass the length of this optimal path. Wiener, Ehbauer, and Mallot (2007) had participants navigate between 25 differently marked cardboard pillars in an experimental room, aiming for the shortest possible path between a set of up to 9 different items. They found that average surpassing of the optimal path length was just over 5\%, and for the most complex routes, the percentage above optimal (PAO) was on average less than $10 \%$. Furthermore, they found that when the target locations were clearly marked, thus diminishing mental load, participants ‘ performance improved even further. Similar studies have been carried out in visual tasks where participants try to connect the dots in as short a path as possible, using paper and pencil (MacGregor \& Ormerod, 1996, 1999), and computerized tasks (Graham Joshi, \& Pizlo, 2000; Vickers, Bovet, Lee, \& Hughes, 2003). The percentage above optimal path length in those studies ranged from $0 \%$ for the simplest tasks up to $10 \%$ for the most complex tasks.

\section{The Current Study}

Few studies have investigated children's organization abilities as they search for multiple targets, even though such abilities may explain to some extent the age effects found in cross-sectional studies of visual search (see e.g. Burggraaf et al., 2019; Woods et al., 2013). Here, we compare the foraging organization of five age groups, ranging from $1^{\text {st }}$ graders to adults, administering both feature and conjunction foraging tasks. We use four measures of organizational abilities: The mean intertarget distance, the number of intersections, the best-r, and the deviation from the optimal path length (percent above optimal: PAO). We hypothesize that in line with results from Woods et al. (2013), organizational abilities will improve into adulthood, and that they will be connected with other aspects of foraging 
performance, in both the feature and conjunction foraging tasks. In addition, we expect that the feature foraging task will be completed in a more organized manner than the conjunction task, as the task requires less effort, and mental load affects path length (see Wiener et al., 2007).

\section{Method}

\section{Participants}

A total of 66 children and 23 adults participated in the experiment. The children were divided into four age groups, three school years apart from each other (see Table 1). Data from three adult participants was excluded due to color blindness. All remaining participants had normal or corrected to normal eyesight.

The children attended two different schools in the same school district in Reykjavik. Consent forms were sent home with all the children for their parents to sign, along with further information about the study. Children in grades 7 and 10 were asked to sign the consent forms as well as their parents, but verbal assent was obtained from younger participants. No compensation was offered to the children for their participation. The adult participants were students in an undergraduate class in psychology. They were offered class credit for participating in the study.

Table 1. Participants.

\begin{tabular}{llllll}
\hline Age group & $\mathrm{N}$ & $\begin{array}{l}\text { Mean age } \\
\text { (years) }\end{array}$ & $\begin{array}{l}\text { Age span } \\
\text { (years) }\end{array}$ & $\begin{array}{l}\text { Sd } \\
\text { (years) }\end{array}$ & Gender \\
\hline First grade & 18 & 6.24 & $5.84-6.69$ & 0.30 & 10 girls/8 boys \\
Fourth grade & 16 & 9.44 & $9.06-9.78$ & 0.22 & 11 girls $/ 5$ boys \\
Seventh grade & 16 & 12.29 & $11.92-12.78$ & 0.27 & 11 girls $/ 5$ boys \\
Tenth grade & 16 & 15.42 & $14.93-15.81$ & 0.28 & 12 girls $/ 4$ boys \\
Adult & 20 & 25.55 & $21.88-48.63$ & 6.03 & 12 female $/ 8$ male \\
\hline
\end{tabular}


All aspects of the experiment were reviewed and approved by the data protection authority of Iceland, the Icelandic National Bioethics Committee, (project number VSN-18055) and permission was granted by the Reykjavik Department of Education and Youth, as well as school administrations from both schools.

\section{Equipment}

The task was presented on an iPad 2 with screen dimensions of $20 \times 15 \mathrm{~cm}$ and an effective resolution of $1024 \times 768$ pixels. It was placed in landscape mode on a table in front of participants, with approximately $50 \mathrm{~cm}$ viewing distance. Stimulus presentation and response collection were carried out with a custom iPad application written in Swift using Xcode.

\section{Stimuli}

The display consisted of 40 stimuli on a black background, 20 targets and 20 distractors. In the feature foraging condition, the stimuli were discs of four different colors, blue, yellow, green, and red. The targets were either the green and red dots and the blue and yellow dots distractors, or vice versa. In the conjunction foraging condition, the stimuli were red and green discs and squares (see Figure 1). The targets were either the red disks and green squares and the distractors the green disks and red squares or vice versa. Their diameter was 20 pixels (approximately $0.46^{\circ}$ visual angle). They were randomly distributed on a nonvisible $10 \times 8$ grid and offset from the edge of the screen by $100 \times 150$ pixels. The viewing area was therefore $12 \times 15 \mathrm{~cm}$ (approximately $13.7 \times 17.1^{\circ}$ ). The position of each item within the grid was randomized by adding a random vertical and horizontal offset. Gaps between columns and rows ensured that items never occluded or touched one another. The location of the targets and distractors was randomly generated from trial to trial. 

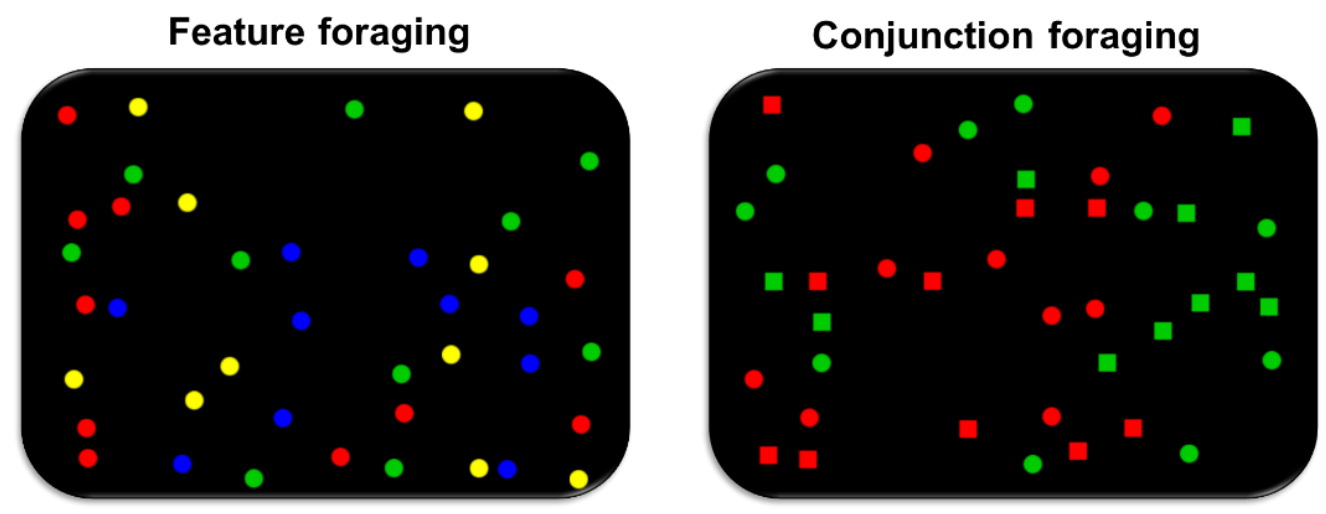

Figure 1. Screenshots of the foraging task. Feature foraging is shown on the left, conjunction foraging on the right.

\section{Procedure}

The experiment was run in a quiet room with normal illumination. The children were visited at school while adult observers were tested in a lab at the University of Iceland.

Observers were required to fully complete ten error-free feature and ten error-free conjunction foraging trials, as well as a few tasks that were administered for the purpose of a different study (see Ólafsdóttir et al., 2020). The first and fourth graders finished the foraging task in a 20-25-minute session and the other tasks in a different session. The older children and adults finished all tasks in a single 40-50-minute session. The foraging task constituted around 15-20 minutes of the session. The first trial of each foraging condition was regarded as a practice trial and the remaining nine constituted the experiment itself. Observers were instructed to use the index finger of their dominant hand to tap all targets as quickly as they could and avoid tapping distractor items. They were informed that they could take a break between any two trials. On the feature foraging trials, the targets were red and green discs and the distractors blue and yellow discs for half of the observers, and vice versa for the other half. On the conjunction foraging trials the targets were red discs and green squares, and the distractors were green discs and red squares for half of the observers, and the reverse applied to the other 
half. The order of foraging conditions as well as target/distractor colors were counterbalanced across each age group.

Each trial was started by tapping anywhere on the screen. The targets disappeared upon being tapped. When every target in the display had disappeared, a smiley face appeared in the middle of the screen along with information about how many trials had been completed and the total time it had taken to complete the previous trial. If a distractor item was tapped, an error message appeared and the trial was restarted, with a new item positions generated randomly.

\section{Data Analysis}

The first fully completed trial of each foraging condition was treated as a practice trial and removed from the dataset, along with all error trials. The organizational measures included best-r, intertarget distance, the number of intersections, and the percentage of path length surpassing the optimal foraging path throughout the display (percentage above optimal, PAO).

Best-r is a measure of the overall path structure or the systematicity of the foraging path of each trial. People typically forage in a systematic way in a static foraging display, for example going through it in columns or rows (Dalmaijer et al., 2015; Kristjánsson et al., 2020; Kristjánsson, Ólafsdóttir, \& Kristjánsson, 2019; Mark, Woods, Ball, Roth, \& Mennemeier, 2004; Woods et al., 2013). Figure 2 shows examples of structured and unstructured foraging path through a display of 40 red and green target items among 40 blue and yellow distractors. The best-r is found by calculating the Pearson correlation coefficient (r) from separate linear regressions of the $\mathrm{x}$ and $\mathrm{y}$ coordinates of the targets, relative to the order in which they are selected. The higher r-value (out of the $\mathrm{x}$ - or y-regressions) constitutes the best-r for a given trial. It is important to note that it is possible to have a highly organized path structure which yields a low best-r value, such as going in a circle around the display or back and forwards in 
an L shaped path. While such strategies are hard to deal with statistically, they would presumably not affect our other organizational measures to any great extent, yielding low intertarget distances, few intersections, and a low surpassing of the optimal path length. Notably, visual inspection of the foraging path on each trial has not revealed any such strategies.

a)

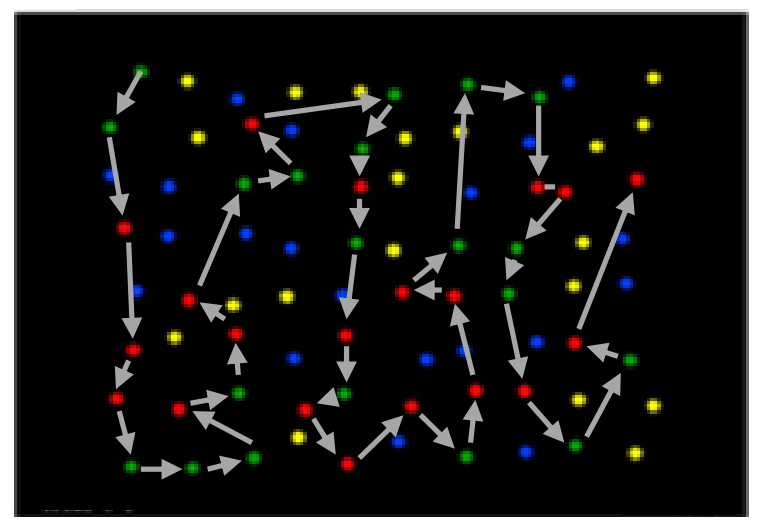

b)

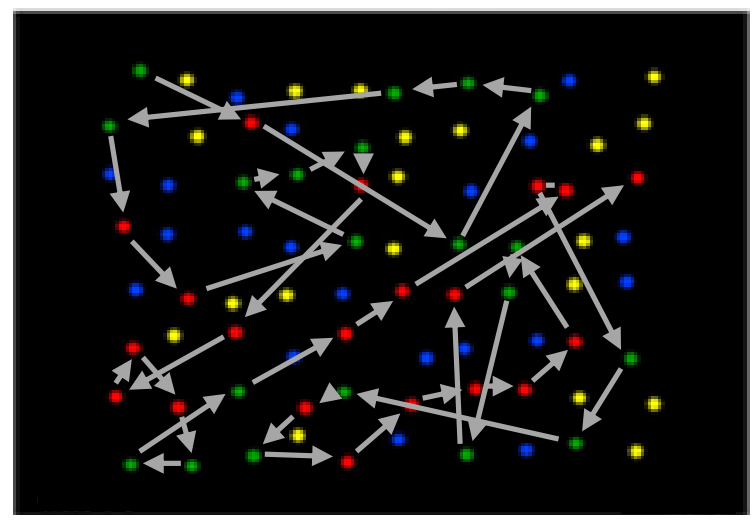

Figure 2. Examples of structured (panel a) and unstructured (panel b) foraging paths with the same start and end points. Panel a shows a trial where an observer searches systematically through columns of the foraging display. In this example, the overall path is consistently moving rightwards, which would result in a high $r$-value for the $\mathrm{x}$-axis. Panel $\mathbf{b}$ shows an unstructured path which should result in a low $\mathrm{r}$-value on both the $\mathrm{x}$ and $\mathrm{y}$ - axes.

Intertarget distance is the mean Euclidean distance between consecutively selected targets, measured in pixels here, and intersections constitute the number of times the foraging path intersects itself on each trial. Well/Highly organized foraging should constitute moving to the most proximal target, resulting in short intertarget distances and a minimal amount of revisiting already covered sections of the display, minimizing the number of intersections (see Figure 2). 
We calculated the optimal foraging path through each display by modifying the ORTools 7.2 code (Perron \& Furnon, 2019), reiterating the code for each possible endpoint in the display. The optimal path is defined as the shortest path through the display starting from the first target selected on each trial, but with no predefined endpoint. The percentage above the optimal foraging path (PAO) on each trial was then calculated by dividing the length of the travelled path by the optimal length, subtracting 1, and multiplying by 100 (see Wiener et al., 2007, for similar methods) VANTAR PUNKT

Age differences in foraging organization were assessed with repeated measures/mixed models? ANOVAS with foraging condition as a within-subject and age group as a betweensubject factor and the organization measures as dependent variables. A Greenhouse-Geisser correction was used to correct for sphericity.

Lastly, to see how foraging organization relates to other foraging measures, a series of single linear regressions were conducted. To correct for multiple comparisons, the $p$-value of each regression was multiplied by the number of comparisons. Analyses were carried out with SPSS, JASP and R.

\section{Results}

The aim of this study was to investigate age differences in foraging organization, in other words, whether the systematicity of the movement pattern through the foraging path would increase with age. There are two foraging paradigms in this study, feature and conjunction foraging. The conjunction foraging task is more demanding and places a higher mental load onto the observers completing the task. Another aim was to find out whether there were differences in organization between these two paradigms, and if so, whether these differences were due to mental load. Lastly, the connection between organization and other aspects of foraging was measured. 


\section{Age differences in foraging organization}

Figure 3 shows that the foraging paths were more structured in the feature than conjunction foraging for all age groups, and older participants went through the foraging displays in a more structured way than the younger participants. A repeated measures ANOVA with group as a between subjects factor revealed a significant difference of the best$\mathrm{r}$ between feature and conjunction foraging, $\mathrm{F}(1,81)=104.36, p<0.001, \eta_{p}{ }^{2}=0.563$ and a significant age difference, $\mathrm{F}(4,81)=7.25, p<0.001, \eta_{p}{ }^{2}=0.264$, but no interaction between foraging task and age $\left(p=0.134, \eta_{p}^{2}=0.082\right)$.

A Holm corrected post hoc comparison revealed a significant difference in best-r on feature foraging trials between adults and $1^{\text {st }}$ graders, $t=-4.49, p<0.001$, Cohen's $\mathrm{d}=-0.484$, adults and $4^{\text {th }}$ graders $t=-3.44, p=0.021$, Cohen's $\mathrm{d}=-0.371$, and adults and $7^{\text {th }}$ graders $t=-$ $3.82, p=0.006$, Cohen's $d=-0.412$. A significant difference in best-r on conjunction foraging trials was found between $7^{\text {th }}$ graders and adults, $t=-3.67, p=0.010$, Cohen's $d=-0.395$.

Figure 3 shows the mean intertarget distance for each age group in panel $b$. The intertarget distance decreased with participants` age, and in each age group the distance was larger in the conjunction foraging task. A repeated measures ANOVA revealed a significant difference in intertarget distance between feature and conjunction foraging trials, $\mathrm{F}(1,81)=$ 138.41, $p<0.001, \eta_{p}{ }^{2}=0.631$ and a significant age difference, $\mathrm{F}(4,81)=8.11, p<0.001, \eta_{p}{ }^{2}$ $=0.286$, but no interaction between foraging task and age $\left(p=0.986, \eta_{p}{ }^{2}=0.004\right)$. Holm corrected post hoc comparisons revealed significant differences between $1^{\text {st }}$ graders and adults in both feature and conjunction foraging, $t=4.54, p<0.001$, Cohen's $\mathrm{d}=0.490$, and $t=4.48$, $p<0.001$, Cohen's d $=0.483$, respectively.

There was also a significant age difference in the number of intersections, $F(4,81)=$ 15.67, $p=0.011, \eta_{p}{ }^{2}=0.148$ but no difference between the two foraging conditions and no interaction between age and foraging task $(p s=0.536$ and 0.371 , respectively; see Figure 3, 
panel c). Holm corrected post hoc tests show significant differences between $1^{\text {st }}$ and $7^{\text {th }}$ graders, $t=3.37, p=0.043$, Cohen's $\mathrm{d}=0.363$, and $1^{\text {st }}$ and $10^{\text {th }}$ graders, $t=3.66, p=0.016$, Cohen's $d=0.395$ on conjunction foraging trials. No significant age differences were found in the feature task (all $p \mathrm{~s}=1.00)$.

A repeated measures ANOVA with group as a between subjects factor revealed a significant difference in the PAO between feature and conjunction foraging, $F(1,81)=$ 159.72, $p<0.001, \eta_{p}{ }^{2}=0.663$ and a significant age difference, $\mathrm{F}(4,81)=8.48, p<0.001, \eta_{p}{ }^{2}$ $=0.295$, but no interaction between foraging task and age $\left(p=0.971, \eta_{p}{ }^{2}=0.006\right)$. Panel d of Figure 3 shows how the PAO decreased with each age group, and how it was smaller on feature than conjunction foraging trials in all age groups. Holm corrected post hoc comparisons showed significant differences of PAO between $1^{\text {st }}$ graders and adults, $t=5.04, p$ $<0.001$, Cohen's $\mathrm{d}=0.544$, and $7^{\text {th }}$ graders and adults, $t=3.29, p=0.032$, Cohen's $\mathrm{d}=0.354$, in the feature foraging task, and between $1^{\text {st }}$ graders and adults in the conjunction foraging task, $t=4.31, p=0.001$, Cohen's $\mathrm{d}=0.465$. 
a)

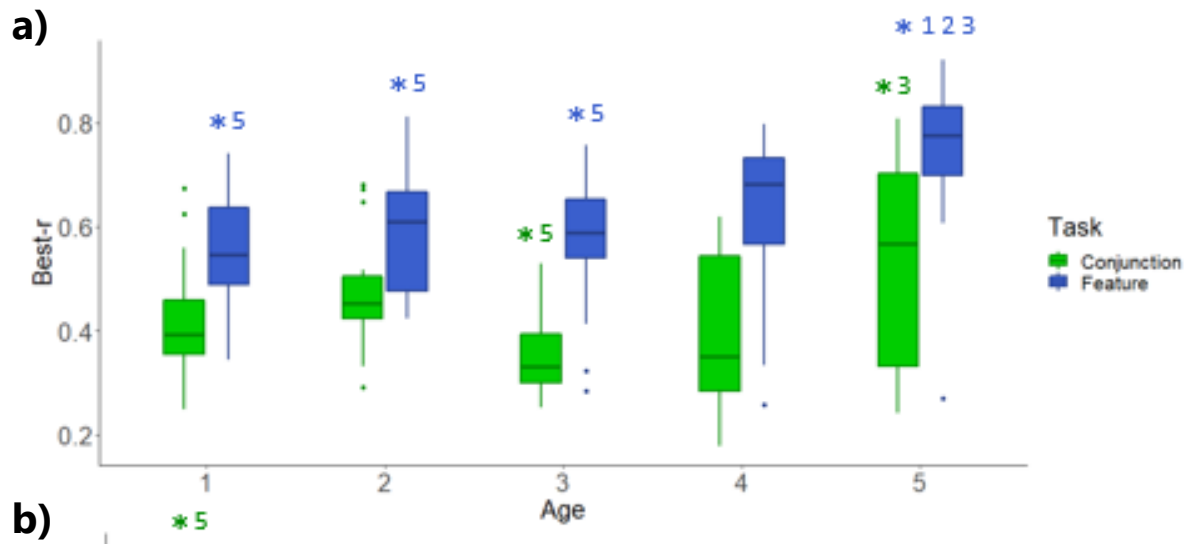

b)

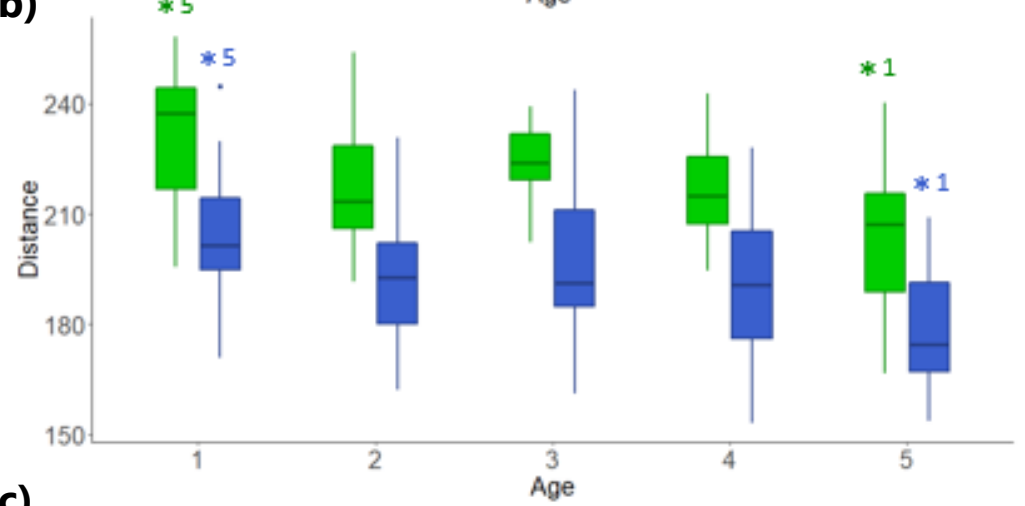

c)

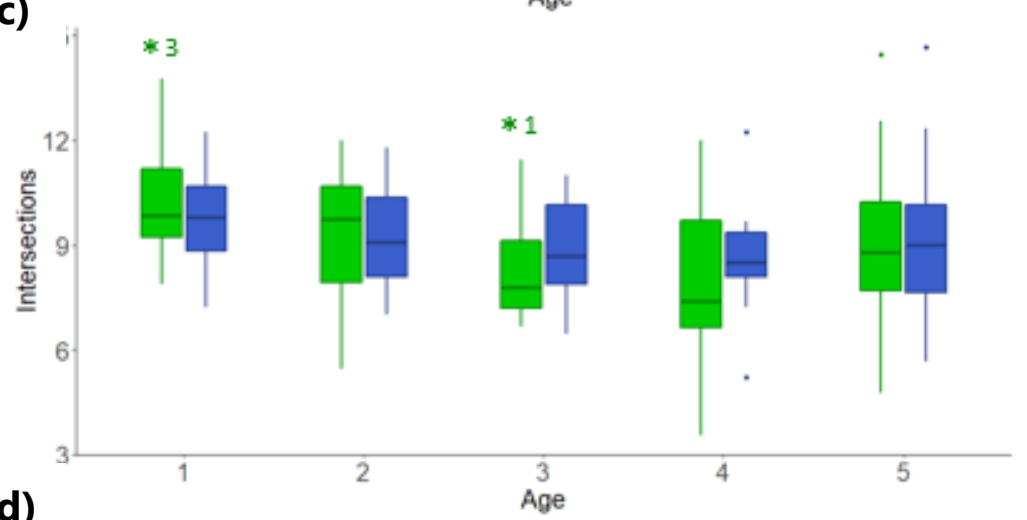

d)

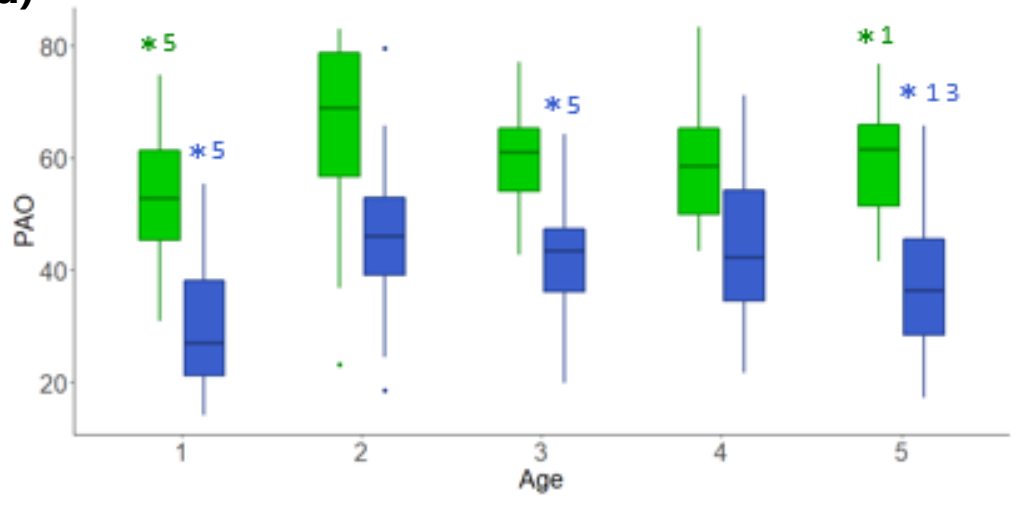

Figure 3. The four organizational measures shown by age and foraging task. Panel a shows the distribution of the best-r of each age group in feature and conjunction foraging. Best-r is a measure of the systematicity of the movement pattern on each trial, the higher the best-r, the more systematic the path through the target items. Panel b shows intertarget distance in pixels in each foraging task divided between age groups. Lower intertarget distances should reflect more organized foraging paths. Panel c shows the number of intersections per trial. In organized paths, there should be few intersections. Panel d shows the surpassing of the 
optimal path through the display in percentages. $\mathrm{PAO}=$ Percent above optimal. A low PAO represents a path that is close to optimal, a high PAO indicates a large deviation from the most optimal path through the display. Groups: $1=1^{\text {st }}$ grade, $2=4^{\text {th }}$ grade, $3=7^{\text {th }}$ grade, $4=$ $10^{\text {th }}$ grade, $5=$ adults. Significant post hoc tests are reflected by asterisks, numbers next to asterisks refer to which age group/s differ significantly from the marked one.

\section{Conjunction foraging - two trials per display?}

Three out of four organizational measures showed more organized feature than conjunction foraging. Previous research using the foraging task developed by Kristjánsson et al. (2014) has shown that most people complete the conjunction foraging task in two runs, that is, they exhaustively forage for all targets of one type, before turning to the other type (see e.g. Kristjánsson et al., 2014; Kristjánsson, Thornton, Chetverikov, \& Kristjánsson, 2020; Jóhannesson, Thornton, Smith, Chetverikov, \& Kristjánsson., 2016; Ólafsdóttir et al., 2019; but see also Kristjánsson, Thornton, \& Kristjánsson, 2018, for some exceptions). The current task is a simplified version of the Kristjánsson et al. (2014) task, with 40 rather than 80 items on the screen. Regardless, all age groups completed the conjunction foraging trials in fewer runs than the feature foraging trials, and a large percentage of conjunction trials were completed in just two runs (see Table 2). It is therefore possible that observers effectively treated the conjunction foraging task as two consecutive foraging tasks displayed on the same screen, where participants complete one task at a time in a highly organized manner. If that is the case, it is problematic to treat the two resulting foraging paths per trial as a single path. We tested this by calculating the PAO and best-r separately for each target type per trial. The PAO was found by reiterating the OR-Tools 7.2 code (Perron \& Furnon, 2019) and finding the optimal path length for each target color separately, as well as the travelled path through the targets of each type. We then calculated by how much the participants surpassed the optimal path, this time for each target type. Since we were dividing the length of each trial in half and wanted to compare those results with the results obtained by treating each trial as a 
single path, we added found the sum the surpassing of the optimal path length of each target type per trial tegether and then calculated the PAO using the same method as before.

Cutting the number of targets in half does not affect best-r in the same way as the PAO, since it is a measure of systematicity but not path length. Therefore, we found the best-r for each target type separately and then calculated their mean to end up with a single best-r measure for each trial. We then compared these new, separated PAO and best-r measures to the overall conjunction and feature trial results (see Figure 4).

A repeated measures ANOVA showed a significant difference between the PAO of overall feature, overall conjunction and separated conjunction foraging, $F(1.89,153.16)=$ 92.26, $p<0.001, \eta_{p}{ }^{2}=0.53$, as well as age differences, $\mathrm{F}(4,81)=7.98, p<0.001, \eta_{p}{ }^{2}=0.28$, and a significant interaction between PAO and age, $\mathrm{F}(7.56,153.16)=2.43, p=0.019, \eta_{p}{ }^{2}=$ 0.11. Post hoc analyses revealed a significant difference between the overall feature and conjunction tasks for every age group, all $p \mathrm{~s}<0.001$, all Cohen's $\mathrm{ds}>0.539$. There was also a significant difference between overall and separated conjunction trials for $1^{\text {st }}$ graders: $t=5.27$, $p<0.001$, Cohen's $\mathrm{d}=0.568,4^{\text {th }}$ graders: $t=4.29, p=0.002$, Cohen's $\mathrm{d}=0.463,7^{\text {th }}$ graders: $t$ $=7.11, p=<0.001$, Cohen's $\mathrm{d}=0.767$, and $10^{\text {th }}$ graders: $t=5.83, p=<0.001$, Cohen's $\mathrm{d}=$ 0.628 , but not for adults, $p=0.214$, Cohen's $\mathrm{d}=0.317$. Lastly, there was a significant difference between feature foraging trials and the conjunction foraging trials with separated target types in the adult group, $t=-3.48,, p=0.042$, Cohen's $\mathrm{d}=-0.376$, but no other group.

Separating target types had a similar effect on the best-r, there was a significant difference between foraging tasks, $\mathrm{F}(1.94,157.27)=150.27, p>0.001, \eta_{p}{ }^{2}=0.650$, age groups, $\mathrm{F}(4,81)=10.38, p>0.001, \eta_{p}{ }^{2}=0.339$, and a significant interaction between task and age, $\mathrm{F}(7.77,157.27)=2.06, p=0.045, \eta_{p}{ }^{2}=0.092$. Post hoc analyses revealed a significant difference between overall feature and conjunction foraging for all age groups except $4^{\text {th }}$ 
graders, all significant $p \mathrm{~s}<0.016$, Cohen's $d=-0.400,-0.611,-0.640$, and -0.705 for $1^{\text {st }}, 7^{\text {th }}$ and $10^{\text {th }}$ graders, and adults, respectively, $p=0.127$, Cohen's $d=-0.325$ for $4^{\text {th }}$ graders.

Table 2. Descriptive statistics for run numbers.

\begin{tabular}{lcccc}
\hline Group & Task & Mean & Sd & Percent \\
\hline $1^{\text {st }}$ grade & $\mathrm{F}$ & 6.00 & 2.75 & 13.0 \\
$4^{\text {th }}$ grade & $\mathrm{F}$ & 6.99 & 2.69 & 5.6 \\
$7^{\text {th }}$ grade & $\mathrm{F}$ & 6.77 & 3.21 & 13.2 \\
$10^{\text {th }}$ grade & $\mathrm{F}$ & 7.19 & 3.54 & 18.8 \\
Adult & $\mathrm{F}$ & 9.10 & 2.93 & 5.0 \\
\hline $1^{\text {st }}$ grade & $\mathrm{C}$ & 3.83 & 2.28 & 43.2 \\
$4^{\text {th }}$ grade & $\mathrm{C}$ & 4.79 & 3.52 & 34.0 \\
$7^{\text {th }}$ grade & $\mathrm{C}$ & 3.01 & 1.91 & 66.7 \\
$10^{\text {th }}$ grade & $\mathrm{C}$ & 3.65 & 2.57 & 59.7 \\
Adult & $\mathrm{C}$ & 5.55 & 3.14 & 32.2 \\
\hline
\end{tabular}

Note: $\mathrm{F}=$ feature foraging, $\mathrm{C}=$ conjunction foraging. Percent $=$ percentage of trials completed in two runs.

There was a significant difference between overall and separated conjunction trials for all age groups, all $p s<0.001$, Cohen's d ranges from -0.642 to -0.982 . A significant difference was found between the overall feature and separated conjunction trials for the $7^{\text {th }}$ graders, $p=0.036$, Cohen's $\mathrm{d}=-0.372$, but not for any other age group, all $p \mathrm{~s}>0.089$.

a)

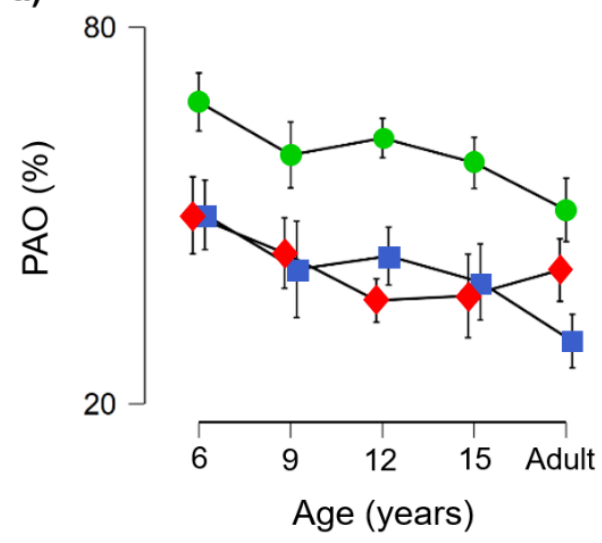

b)

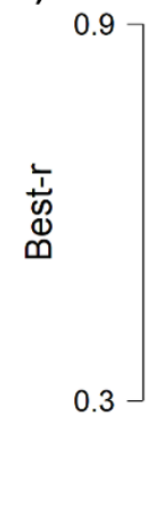

Foraging task:

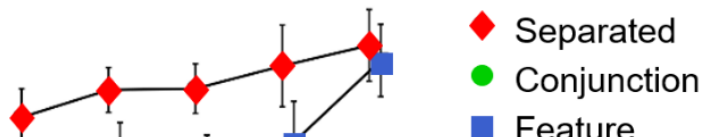

- Feature

Figure 4. The difference between the PAO (panel a) and best-r (panel b) on overall feature foraging trials (blue squares), overall conjunction foraging trials (green dots) and conjunction foraging trials where organization was calculated separately between target 1 and 2 and then added together (red diamonds). Groups: $1=1^{\text {st }}$ grade, $2=4^{\text {th }}$ grade, $3=7^{\text {th }}$ grade, $4=10^{\text {th }}$ grade, $5=$ adults. 


\section{Is foraging organization connected to any other foraging measures?}

Table 3 shows the mean and standard deviation of various foraging measures (for extensive analyses of these measures, see Ólafsdóttir et al. 2020). The intertarget times (ITTs) are a measure of foraging speed, or the time that passes between each tap on a target. Switch costs are the differences of intertarget times between selecting the same target as previously or switching between target types. As can be seen in Table 3, switching between target types usually involves slower ITTs than repeatedly selecting the same target type, especially in the conjunction foraging task. The youngest participants also slow down considerably when switching between target types in the feature foraging task. Runs are a measure of how often participants switch between target types. One run is defined as a repeated selection of the same target type. When a participant switches between target types a new run is started. Therefore, the number of runs per trial constitutes the number of switches +1 (the first run, which is not counted as a switch). Errors is the mean number of errors that are made as observers attempt to finish 10 trials.

Table 3. Mean and SD of each age group for various foraging measures.

Feature foraging

\begin{tabular}{|c|c|c|c|c|c|c|c|c|}
\hline \multirow[b]{2}{*}{ Group } & \multicolumn{2}{|c|}{ ITTs (ms) } & \multicolumn{2}{|c|}{ Switch costs (ms) } & \multicolumn{2}{|c|}{ Runs } & \multicolumn{2}{|c|}{ Errors } \\
\hline & Mean & SD & Mean & SD & Mean & SD & Mean & SD \\
\hline 1 & 809.47 & 130.18 & 315.54 & 231.78 & 6.00 & 1.68 & 1.22 & 1.22 \\
\hline 2 & 580.26 & 106.53 & 191.87 & 158.81 & 7.02 & 1.60 & 1.50 & 1.67 \\
\hline 3 & 433.54 & 84.94 & 98.34 & 84.56 & 6.76 & 2.06 & 0.63 & 0.81 \\
\hline 4 & 377.69 & 88.29 & 82.15 & 137.70 & 7.19 & 2.76 & 0.63 & 0.72 \\
\hline 5 & 377.93 & 57.08 & 36.61 & 40.79 & 9.09 & 2.11 & 0.26 & 0.56 \\
\hline
\end{tabular}

Conjunction foraging

\begin{tabular}{ccccccccc}
\hline & \multicolumn{2}{c}{ ITTs } & \multicolumn{3}{c}{ Switch costs } & \multicolumn{2}{c}{ Runs } & \multicolumn{2}{c}{ Errors } \\
\cline { 2 - 9 } Group & Mean & SD & Mean & SD & Mean & SD & Mean & SD \\
\cline { 2 - 9 } 1 & 1062.72 & 210.85 & 1067.66 & 562.68 & 3.92 & 1.58 & 7.61 & 4.94 \\
2 & 743.48 & 123.09 & 719.30 & 546.91 & 4.91 & 2.24 & 7.06 & 7.58 \\
3 & 516.66 & 112.47 & 444.21 & 292.62 & 3.09 & 1.20 & 3.00 & 3.63 \\
4 & 479.05 & 111.99 & 397.73 & 317.60 & 3.67 & 2.10 & 1.31 & 1.54 \\
5 & 535.41 & 106.56 & 404.90 & 385.72 & 5.51 & 2.69 & 1.11 & 1.37 \\
\hline
\end{tabular}


Woods et al. (2013) studied search organization with a paper and pencil cancellation task and showed that organizational abilities are connected to accuracy in conjunction search, concluding that children's lack of ability to plan and execute organized search affected their conjunction search abilities. The paper and pencil task used in their study can be defined as a foraging task, as the participants were instructed to find 16 target items embedded within a number of distractors. In an attempt to replicate and build upon their findings, we assessed whether foraging organization is connected to other foraging measures with a series of single linear regressions (see Tables 4 and 5). As Table 4 shows, the error rates are not connected to any organizational measure, but three out of the four organizational measures are connected with other foraging measures, such as foraging speed (ITTs), how often participants switch between target types (runs) and the cost of switching.

We did not replicate Woods et al.'s finding about the connection between error rates and conjunction search organization (see Table 5). But the other three foraging measures were connected with best-r, intertarget distance, and PAO, but not the number of intersections.

Table 4. Linear regressions on foraging organization and other measures in the feature foraging task.

\begin{tabular}{llcccc}
\hline & & $\mathrm{B}$ & $\mathrm{t}$ & $\mathrm{p}_{\text {corr }}$ & Adjusted $\mathrm{R}^{2}$ \\
\hline Best-r & Runs & 0.83 & 13.66 & $<\mathbf{0 . 0 0 1}$ & 0.686 \\
& ITTs & -0.31 & -3.03 & 0.05 & 0.088 \\
& Switch costs & -0.54 & -5.87 & $<\mathbf{0 . 0 0 1}$ & 0.282 \\
& Errors & -0.04 & -0.37 & $>0.71$ & -0.010 \\
\hline Target distance & Runs & -0.81 & -12.77 & $<\mathbf{0 . 0 0 1}$ & 0.656 \\
& ITTs & 0.35 & 3.47 & $\mathbf{0 . 0 1}$ & 0.115 \\
& Switch costs & 0.61 & 7.03 & $<\mathbf{0 . 0 0 1}$ & 0.363 \\
& Errors & 0.02 & 0.19 & $>0.85$ & -0.011 \\
\hline Intersections & Runs & 0.12 & 1.06 & $>0.29$ & 0.001 \\
& ITTs & 0.17 & 1.59 & $>0.12$ & 0.018 \\
& Switch costs & 0.09 & 0.85 & $>0.40$ & -0.003 \\
& Errors & 0.06 & 0.52 & $>0.60$ & -0.009 \\
\hline PAO & Runs & -0.82 & -13.29 & $<\mathbf{0 . 0 0 1}$ & 0.674 \\
& ITTs & 0.39 & 3.91 & $\mathbf{0 . 0 0 3}$ & 0.144 \\
& Switch costs & 0.60 & 6.93 & $<\mathbf{0 . 0 0 1}$ & 0.356 \\
& Errors & 0.05 & & $>0.68$ & -0.010 \\
\hline
\end{tabular}

Note: $\mathrm{B}=$ Standardized $\beta, \mathrm{p}_{\text {corr }}=\mathrm{p}$ values corrected for multiple comparisons. PAO = percentage above optimal. Significant $p$-values are displayed in bold. A $p$-value approaching significance is shown in italics. All DF $=84$. 
Table 5. Linear regressions on foraging organization and other measures in the conjunction foraging task.

\begin{tabular}{llcccc}
\hline & & $\mathrm{B}$ & $\mathrm{t}$ & $\mathrm{p}_{\text {corr }}$ & Adjusted $\mathrm{R}^{2}$ \\
\hline Best-r & Runs & 0.81 & 12.72 & $<\mathbf{0 . 0 0 1}$ & 0.654 \\
& ITTs & 0.05 & 0.45 & $>0.65$ & -0.009 \\
& Switch costs & -0.34 & 3.33 & $\mathbf{0 . 0 2 0}$ & 0.106 \\
& Errors & 0.08 & 0.73 & $>0.47$ & -0.006 \\
\hline Target distance & Runs & -0.51 & -5.48 & $<\mathbf{0 . 0 0 1}$ & 0.254 \\
& ITTs & 0.32 & 3.09 & $\mathbf{0 . 0 4}$ & 0.091 \\
& Switch costs & 0.50 & 5.23 & $<0.001$ & 0.237 \\
& Errors & 0.15 & 1.35 & $>0.18$ & 0.009 \\
\hline Intersections & Runs & 0.45 & 4.59 & $<\mathbf{0 . 0 0 1}$ & 0.191 \\
& ITTs & 0.46 & 4.76 & $<\mathbf{0 . 0 0 1}$ & 0.203 \\
& Switch costs & 0.09 & 0.80 & $>0.43$ & -0.004 \\
& Errors & 0.30 & 2.83 & 0.09 & 0.076 \\
\hline PAO & Runs & -0.51 & -5.44 & $<\mathbf{0 . 0 0 1}$ & 0.252 \\
& ITTs & 0.30 & 2.93 & 0.07 & 0.082 \\
& Switch costs & 0.53 & 5.71 & $<\mathbf{0 . 0 0 1}$ & 0.271 \\
& Errors & 0.16 & 1.51 & $>0.13$ & 0.015 \\
\hline
\end{tabular}

Note: $\mathrm{B}=$ Standardized $\beta, \mathrm{p}_{\text {corr }}=\mathrm{p}$ values corrected for multiple comparisons. $\mathrm{PAO}=$ percentage above optimal. Significant $p$-values are displayed in bold.

\section{Discussion}

The aims of this study were threefold: First, to investigate how foraging organization changes with increasing age. Second, to study the differences between foraging organization in an easy feature foraging task and a difficult conjunction foraging task, and third, to estimate the connection between foraging organization and other aspects of foraging abilities. Due to the large number of variables and tests in this study, the following discussion will focus on main effects of age and task difficulty on organization.

\section{Foraging organization increases with age}

We found that organizational abilities increase with age in both feature and conjunction foraging based tasks. In both tasks the pattern of improvement is the same, a gradual increase of organizational abilities from the youngest participants and until adulthood on three out of four measures: best-r, intertarget distance, and PAO. The best-r is a measure of 
how systematic the travelled path is on each trial, when the path goes systematically in columns or rows from e.g. left to right, or top to bottom, the best-r is high. If there is no evident structure in the travelled path the best-r will be low. On average, the older participants were more systematic in their foraging than the younger age groups. The intertarget distance of the older participants was also shorter, and their surpassing of the shortest possible path through the display lower. There were also age differences in the number of intersections per trial, but unlike the other measures, they seem to level off by $7^{\text {th }}$ grade, or at the age of 12 . To summarize, the $1^{\text {st }}$ and $4^{\text {th }}$ grade participants have the least structured foraging paths, with more instances of the path intersecting itself than the older age groups, resulting in longer intertarget distances and a high PAO. The travelled path continues to become more structured and shorter between age groups, with the adults being the most organized foragers. These results are in accordance with a study by Woods and colleagues (2013) who found a gradual increase in organizational abilities of children aged 2-18 years completing a paper and pencil cancellation task, which slowed down considerably by the age of 12 .

Previous studies using PAO or other forms of optimal path analyses, have found that people are remarkably efficient in finding the optimal path through a display (MacGregor \& Ormerod, 1996; MacGregor et al.,1999; Wiener et al., 2006). Finding the optimal path is known as the travelling salesman problem in mathematics and computer science, and is an NP-hard problem, meaning that there is no efficient way of reaching a solution (Graham et al., 2000; Wiener et al., 2006). In previous studies on the travelling salesman problem, people rarely surpass the optimal path by more than $10 \%$, regardless of the number of items in the path (Graham et al., 2000; MacGregor \& Ormerod, 1996, MacGregor et al., 1999; Vickers et al., 2003; Wiener et al., 2007). In the current study, the PAO's of adult participants were on average around $20 \%$ for feature foraging but around $50 \%$ for conjunction foraging. Here, we didn't specifically ask our observers to take as short a path as possible, but to perform the task 
quickly without making errors, resulting in longer paths than are known in the aforementioned travelling salesman studies. Regardless, the PAOs of adults are about $20 \%$ lower than those of $1^{\text {st }}$ grade children in both foraging tasks, showing that as organizational abilities mature, people start to optimize the path through the display, without being explicitly asked to do so.

\section{Differences between feature and conjunction foraging}

Organization was better in feature than conjunction foraging in all age groups, on three out of the four measures. There was no difference between the number of intersections during feature and conjunction foraging, but the best-r was higher, intertarget distance lower, and the PAO lower in the feature foraging task. There was no interaction between age and foraging task, which means that the differences between the organization of feature and conjunction foraging are stable throughout development.

The lack of interaction between age and task difficulty may seem surprising, given the myriad of studies showing the opposite, both in the classic visual search literature (e.g. Merrill \& Lookadoo, 2004; Trick \& Enns, 1998) and foraging studies (e.g. Ólafsdóttir et al., 2019, 2020), but previous studies have found similar results regarding the path chosen through a display. Burggraaf et al. (2018) studied visual search in adolescents while tracking their eye movements. They found that although search became more efficient between ages 12 and 19, evident from decreased reaction times while accuracy remained stable, this increased efficiency was due to stimulus fixation times. No age differences were found in either the number of fixations per trial or the selection of fixation locations. This applied to both the single and mixed spatial frequency tasks and no interaction was found between either age and task difficulty or age and the spatial frequency of the target.

Notably, our results reveal differences in organization by age, even during feature foraging. This contradicts the proposal that abilities to detect a target that differs from 
distractors on a single feature are fully developed by birth or very early in development. In single target visual search studies, children's response times are higher than those of adult participants. Search times have been attributed to functions unrelated to visual attention, such as sensory-motor maturation (Donders, 1969; Gerhardstein \& Rovee-Collier, 2002; Trick \& Enns, 1998) and information processing speed (see Kail, 1991 for a review), but see Grubert et al. (2014) for evidence of cognitive development influencing response times into adolescence.

Children's search slopes in feature search, however, are always relatively flat, regardless of the number of distractors in the search display (see e.g. Adler \& Orprecio, 2006; Gerhardstein \& Rovee-Collier, 2002; Rojas-Benjumea et al., 2013; Sireteanu \& Rieth, 1992), leading to the claim that feature processing mechanisms are mature by early infancy. According to our data the development of this ability happens gradually with age (see also Ólafsdóttir et al., 2016, 2019, 2020). Among other things this shows the sensitivity of this foraging task to performance aspects of visual attention, and how it provides additional information above single target search tasks by giving insights into visual orienting over time rather than a single snapshot of visual attention on each trial.

Studies of different aspects of foraging performance, such as foraging speed and accuracy, have showed similar results regarding age and task differences. Previous studies have found that both feature and conjunction foraging abilities are still developing up until around the age of 12 (Ólafsdóttir et al., 2019, 2020), but nevertheless, children's performance is better in feature than conjunction foraging tasks, as is the case for adult participants. Conjunction foraging is both less accurate and slower than feature foraging. Furthermore, both children and adults seem to refrain from switching between target types during conjunction foraging. When switches do occur, large switch costs appear, that is, participants slow down or hesitate before selecting a target that is different from the previous target, 
compared to when they select a target of the same type as the previous one (Kristjánsson et al., 2014; Ólafsdóttir et al, 2019; 2020). This has been explained by increased mental load during conjunction foraging compared with feature foraging, especially with regard to working memory, and we hypothesized that it could be the reason for less organized conjunction foraging. Wiener and colleagues (2007), found that clearly marking the target locations in their real-life travelling salesman task, diminished the PAO considerably. When participants were handed a "shopping list" with between 7 and 9 figures and asked to navigate between these target items in a room filled with 25 pillars, all marked with different figures, the PAO was on average 8.7 , but went down to 2.7 when the target pillars were clearly marked, removing the need to memorize and look for the items from the shopping list. The lower mental load of feature than conjunction foraging could therefore have explained the performance differences between the two tasks.

\section{Why is conjunction foraging less organized?}

Differences between feature and conjunction foraging performance can in most cases be explained by differences in mental load and this could apply to organization as well. Another explanation could be that participants treat the conjunction foraging display as two separate search arrays, first looking for all targets of one type, and then the other. These two separate foraging paths could be highly organized but treating them as a single path in all analyses would result in low scores on all measures. A large part of the conjunction foraging trials was indeed completed in only two runs, and the mean run number during conjunction foraging was low in most age groups. This might indicate that the trials that were completed in over two runs result from a target or two being missed and then collected later, when all other targets had been tapped.

We tested this hypothesis by analyzing the different target types separately, calculating new best-r and PAO scores. We found that the best-r improves considerably in all 
age groups and that the PAO scores improve for all ages except adults. The best-r calculated from the separated target types even surpasses the best-r of the feature foraging of $7^{\text {th }}$ grade children, but there are no other significant differences between the best-r of feature foraging and the separated conjunction foraging. The results were similar when PAO was calculated separately for each target type per trial. The PAO of the separated conjunction foraging trials is considerably lower than the overall PAO in the conjunction task and comparable to the PAO of feature foraging trials in four out of five age groups. The PAO of adults does not change when the target types are separated.

Separating the conjunction trials seems to have a larger effect on the data for the children than adults. Since children tend to complete these trials in fewer runs than adults (see Table 2), children may be more likely to treat these trials as two separate foraging paths. Previous studies have shown that a small proportion of adult participants switch as frequently between target types in conjunction as in feature foraging, and their switch costs are minimal (Kristjánsson, Á. et al., 2014; Kristjánsson, T. et al., 2018; Jóhannesson, Kristjánsson, \& Thornton, 2017). This may reflect a willingness to expend more mental effort rather than superior foraging abilities, because adding time limits to foraging tasks results in increased switching and lower switch costs in conjunction tasks for all participants (Kristjánsson et al., 2018). The foraging tasks in the current study are simplified versions of the tasks administered in previous studies. It is therefore possible that some of the adults in the current sample, even a higher proportion than in earlier studies, did not treat the conjunction task as two separate search paths, but switched often between target types. Separating the different target types in the analyses should therefore not improve the measured organization for those participants, lowering the scores from these analyses for the adult group as a whole. 


\section{Does organization influence other aspects of foraging?}

We found that organization was not only connected to conjunction foraging, but also feature foraging, in terms of speed, the number of runs, and switch costs. In the conjunction foraging task, these measures were connected with every organizational measure used in the study, and in the feature foraging task, every measure except from the number of intersections. This differs from findings that organizational abilities are only connected to performance in conjunction search but not feature search in single target search (Woods et al., 2013). A variety of cognitive processes underlie performance in visual foraging tasks. These results indicate that organizational abilities play an important role in visual orienting and thus influence other aspects of foraging abilities.

Previous foraging studies have shown age differences in feature foraging (Gil-Gómez de Liaño, Quirós-Godoy, Pérez-Hernández, Cain, \& Wolfe, 2018; Ólafsdóttir et al., 2016; 2019; 2020), and a connection between feature foraging and executive functions (Ólafsdóttir et al., 2016; 2019; 2020; Quirós-Godoy, Pérez-Hernández, Cain, Wolfe, \& Gil-Gómez de Liaño, 2018), both of which are in contradiction with findings from single target search tasks, where the differences between children and adults' feature search performance have been negligible (see e.g. Gerhardstein \& Rovee-Collier, 2002; Hommel, Li, \& Li, 2004; Thompson \& Massaro, 1989; Trick \& Enns, 1998; Woods et al., 2013). In the current study, these findings have been extended to organizational abilities.

\section{Summary and conclusions}

Our study shows age differences in the movement patterns throughout foraging displays, where organization increases with rising age, for both feature and conjunction foraging paradigms. Additionally, foraging organization is connected to other aspects of foraging abilities in both foraging tasks, highlighting its importance in successful visual 
orienting. Feature foraging is more organized than conjunction foraging in childhood, adolescence, and adulthood. This can either be an indicator of a higher mental load during conjunction foraging or of participants treating each conjunction foraging trial as two separate search paths. Our analyses indicate the latter, but a new study, with only a single target type may be needed to determine the differences between feature and conjunction foraging organization with more certainty. Ideally, a longitudinal study of various foraging abilities of children should be conducted to gain greater insight into how these abilities and the relationship between them develop.

To conclude, organization seems to play a big part in the development foraging abilities and is a promising avenue for further research. 


\section{Acknowledgements}

This work was supported by the Research Fund of the University of Iceland, grant numbers, 1032397 and 1470-147-2701 and a grant from the Icelandic Research Fund, number 152427051.

\section{Open practices statement}

None of the data or materials for the experiments reported here is publicly available, due to Icelandic data protection laws regarding underaged participants. The experiment was not preregistered. 


\section{References}

Adler, S. A., \& Orprecio, J. (2006). The eyes have it: Visual pop-out in infants and adults. Developmental Science, 9(2), 189-206.

Appelros, P., Karlsson, G. M., Seiger, A., \& Nydevik, I. (2002). Neglect and anosognosia after first-ever stroke: Incidence and relationship to disability. Journal of Rehabilitation Medicine, 34(5), 215-220.

Benjamins, J. S., Dalmaijer, E. S., Ten Brink, A. F., Nijboer, T. C., \& Van der Stigchel, S. (2019). Multi-target visual search organisation across the lifespan: Cancellation task performance in a large and demographically stratified sample of healthy adults. Aging, Neuropsychology, and Cognition, 26(5), 731-748.

Bond, A. B. (1982). The bead game: Response strategies in free assortment. Human Factors, 24(1), 101-110.

Brucki, S. M. D., \& Nitrini, R. (2008). Cancellation task in very low educated people. Archives of Clinical Neuropsychology, 23(2), 139-147.

Burggraaf, R., van der Geest, J. N., Hooge, I. T., \& Frens, M. A. (2019). Developmental changes in visual search are determined by changing visuospatial abilities and task repetition: a longitudinal study in adolescents. Applied Neuropsychology: Child, 1-11.

Buxbaum, L. J., Ferraro, M. K., Veramonti, T., Farne, A., Whyte, J., Ladavas, E., . . Coslett, H. B. (2004). Hemispatial neglect: Subtypes, neuroanatomy, and disability. Neurology, 62(5), 749-756.

Byrd, D. E., Touradji, P., Tang, M.-X., \& Manly, J. T. (2004). Cancellation test performance in African American, Hispanic, and White elderly. Journal of the International Neuropsychological Society, 10, 401-411. 
Cain, M. S., Vul, E., Clark, K., \& Mitroff, S. R. (2012). A Bayesian optimal foraging model of human visual search. Psychological Science, 23(9), 1047-1054. https://doi.org/10.1177/0956797612440460

Dalmaijer, E. S., Li, K. M. S., Gorgoraptis, N., Leff, A. P., Cohen, D. L., Parton, A., . . Malhotra, P. A. (2018). Randomised, double-blind, placebo-controlled crossover study of single-dose guanfacine_in unilateral neglect following stroke. Journal of Neurology, Neurosurgery \& Psychiatry, 89(6):593-598. doi:10.1136/jnnp-2017-317338

Dalmaijer, E. S., Van der Stigchel, S., Nijboer, T. C. W., Cornelissen, T. H. W., \& Husain, M. (2015). CancellationTools: All-in-one software for administration and analysis of cancellation tasks. Behavior Research Methods, 47(4), 1065-1075.

Donders, F. C.(1969). On the speed of mental processes. W. G. Koster (Ed. \& Trans.), Attention and performance, II. Amsterdam: North-Holland. (Original work published 1868).

Dukas, R., \& Ellner, S. (1993). Information processing and prey detection. Ecology, 74, 13371346.

Fabrigoule, C., Rouch, I., Taberly, A., Letenneur, L., Commenges, D., Mazaux, J. M., ... Dartigues, J. F. (1998). Cognitive process in preclinical phase of dementia. Brain, 121(1), 135-141. doi:10.1093/brain/121.1.135

Gainotti, G., Marra, C., \& Villa, G. (2001). A double dissociation between accuracy and time of execution on attentional tasks in Alzheimer's disease and multi-infarct dementia. Brain, 124(4), 731-738. doi:10.1093/brain/124.4.731 
Gerhardstein, P. \& Rovee-Collier, C. (2002). The development of visual search in infants and very young children. Journal of Experimental Child Psychology, 81, 194-215. doi:10.1006/jecp.2001.2649

Gil-Gómez de Liaño, B. G. G., Quirós-Godoy, M., Pérez-Hernández, E., Cain, M., \& Wolfe, J. (2018). Understanding Visual Search and Foraging in Cognitive Development. Journal of Vision, 18(10), 635-635.

Graham, S. M., Joshi, A., \& Pizlo, Z. (2000). The travelling salesman problem: A hierarchical model. Memory \& Cognition, 28(7), 1191-1204.

Grubert, A., Indino, M., \& Krummenacher, J. (2014). From features to dimensions: cognitive and motor development in pop-out search in children and young adults. Frontiers in Psychology, 5, 519. doi.org/10.3389/fpsyg.2014.00519

Hommel, B., Li, K. Z., \& Li, S. C. (2004). Visual search across the life span. Developmental Psychology, 40(4), 545.

Huang, L. \& Pashler. H. (2005). Attention capacity and task difficulty in visual search. Cognition, 94(3), 101-111. https://doi.org/10.1016/j.cognition.2004.06.006

Humphrey, D. G. \& Kramer, A. F. (1997). Age differences in visual search for feature, conjunction, and triple-conjunction targets. Psychology and Aging, 12(4), 704-717. https://doi.org/10.1037/0882-7974.12.4.704

Husain, M., \& Rorden, C. (2003). Non-spatially lateralized mechanisms in hemispatial neglect. Nature Reviews Neuroscience, 4(1), 26-36.

Jóhannesson, Ó.I., Kristjánsson, Á. \& Thornton, I.M. (2017). Are foraging patterns in humans related to working memory and inhibitory control? Japanese Psychological Research, 59, 152-166. doi: 10.1111/jpr.12152 
Jóhannesson, O. I., Thornton, I. M., Smith, I. J., Chetverikov, A., \& Kristjánsson, A. (2016). Visual foraging with fingers and eye gaze. i-Perception, 7(2), 2041669516637279.

Kail, R. (1991). Developmental change in speed of processing during childhood and adolescence. Psychological Bulletin, 109, 490-501.

Kristjánsson, Á. (2015). Reconsidering visual search. i-Perception, 6(6), 2041669515614670.

Kristjánsson, Á., \& Egeth, H. (2020). How feature integration theory integrated cognitive psychology, neurophysiology, and psychophysics. Attention, Perception, \& Psychophysics, 82(1), 7-23.

Kristjánsson, Á., Jóhannesson, Ó. I., \& Thornton, I. M. (2014). Common attentional constraints in visual foraging. PloS one, $9(6)$.

Kristjánsson, Á., Ólafsdóttir, I. M., \& Kristjánsson, T. (2019). Visual foraging tasks provide new insights into the orienting of visual attention: Methodological considerations. In: Pollmann S. (ed). Spatial Learning and Attention Guidance. Neuromethods, 151, Humana, New York, NY. https://doi.org/10.1007/7657 201921

Kristjánsson, T., Draschkow, D., Pálsson, Á., Haraldsson, D., Jónsson, P. Ö., \& Kristjánsson, Á. (2020). Moving foraging into 3D: Feature versus conjunction-based foraging in virtual reality. Quarterly Journal of Experimental Psychology. https://doi.org/10.1177/1747021820937020

Kristjánsson, T., Thornton, I. M., Chetverikov, A., \& Kristjánsson, Á. (2020). Dynamics of visual attention revealed in foraging tasks. Cognition, 194, 104032.

Kristjánsson, T., Thornton, I. M., \& Kristjánsson, Á. (2018). Time limits during visual foraging reveal flexible working memory templates. Journal of Experimental 
Psychology: Human Perception and Performance, 44(6), 827-835.

https://doi.org/10.1037/xhp0000517

Lobaugh, N. J., Cole, S., \& Rovet, J. F. (1998). Visual search for features and conjunctions in development. Canadian Journal of Experimental Psychology/Revue canadienne de psychologie expérimentale, 52(4), 201-212. https://doi.org/10.1037/h0087293

Lowery, N., Ragland, J. D., Gur, R. C., Gur, R. E., \& Moberg, P. J. (2004). Normative data for the_symbol cancellation test in young healthy adults. Applied Neuropsychology, 11(4), 218-221.

MacGregor, J. N. \& Ormerod, T. C. (1996). Human performance on the traveling salesman problem. Perception and Psychophysics, 58, 527-539.

MacGregor, J. N., Ormerod, T. C., \& Chronicle, E. P. (1999). Spatial and contextual factors in human performance on the travelling salesperson problem. Perception, 28(11), 14171427.

Maljkovik, V. \& Nakayama, K. (1994). Priming of pop-out: I. Role of features. Memory \& Cognition, 22, 657-672. https://doi.org/10.3758/BF03209351

Maljkovic, V. \& Nakayama, K. (1996). Priming of pop-out: II. The role of position. Perception \& Psychophysics, 58(7), 977-991. doi:10.3758/bf03206826

Mark, V. W., Woods, A. J., Ball, K. K., Roth, D. L., \& Mennemeier, M. (2004). Disorganized search on cancellation is not a consequence of neglect. Neurology, 63(1), 78-84.

Merrill, E. C. \& Lookadoo, R. (2004). Selective search for conjunctively defined targets by children and young adults. Journal of Experimental Child Psychology, 89, 72-90.

Najemnik, J. \& Geisler, W. (2005). Optimal eye movement strategies in visual search. Nature, 434, 387-391. https://doi.org/10.1038/nature03390 
Nijboer, T. C. W., Kollen, B. J., \& Kwakkel, G. (2013). Time course of visuospatial neglect early after stroke: A longitudinal cohort study. Cortex, 49(8), 2021-2027

Ólafsdóttir, I. M., Gestsdóttir, S., \& Kristjánsson, Á. (2019). Visual foraging and executive functions: A developmental perspective. Acta Psychologica, 193, 203-213.

Ólafsdóttir, I. M., Gestsdóttir, S., \& Kristjánsson, Á. (2020). Age differences in foraging and executive functions: A cross-sectional study. Journal of Experimental Child Psychology.

Ólafsdóttir, I. M., Kristjánsson, T., Gestsdóttir, S., Jóhannesson, Ó. I., \& Kristjánsson, Á. (2016). Understanding visual attention in childhood: Insights from a new visual foraging task. Cognitive Research: Principles and Implications, 1(1), 18.

Pashler, H. (1987). Target-distractor discriminability in visual search. Perception \& Psychophysics, 41, 285-292. https://doi.org/10.3758/BF03208228

Pelegrina, S., Molina, R., Rodríguez-Martínez, E. I., Linares, R., Gómez, C. M. (2020) Agerelated changes in selection, recognition, updating and maintenance information in WM. An ERP study in children and adolescents. Biological Psychology, 157, 107977. DOI: 10.1016/j.biopsycho.2020.107977.

Perron, L. \& Furnon, V. (2019). OR-Tools 7.2. https://developers.google.com/optimization/.

Quirós-Godoy, M., Pérez-Hernández, E., Cain, M., Wolfe, J., \& Gil-Gómez de Liaño, B. (2018). Individual Differences in Visual Search and Foraging in children. Journal of Vision, 18(10), 637.

Rojas-Benjumea, M. Á., Quintero-Gallego, E. A., Zozaya, L., Barriga-Paulino, C. I., \& Gómez, C. M. (2013). Children cautious strategy and variable maturation time window for responding in a visual search task. Psychology, 4(1), 19-32. 
Saykin, A. J., Gur, R. C., Gur, R. E., Shtasel, D. L., Flannery, K. A., Mozley, L. H., . . Mozley, P. D. (1995). Normative neuropsychological test performance: Effects of age, education, gender, and ethnicity. Applied Neuropsychology, 2, 79-88.

Scialfa, C. T. \& Joffe, K. M. (1998). Response times and eye movements in feature and conjunction search as a function of target eccentricity. Perception \& Psychophysics, 60, 1067-1082. https://doi.org/10.3758/BF03211940

Sireteanu, R., \& Rieth, C. (1992). Texture segregation in infants and children. Behavioral Brain Research, 49, 133- 139.

Sævarsson, S., Jóelsdóttir, S., Hjaltason, H., \& Kristjánsson, A. (2008). Repetition of distractor sets improves visual search performance in hemispatial neglect. Neuropsychologia, 46(4), 1161-1169.

Ten Brink, A. F., Visser-Meily, J. M., \& Nijboer, T. C. (2018). What does it take to search organized? the cognitive correlates of search organization during cancellation after stroke. Journal of International Neuropsycholical Society, 24, 424-36.

Thompson, L. A. \& Massaro, D. W. (1989). Before you see it, you see its parts: Evidence for feature encoding and integration in preschool children and adults. Cognitive Psychology, 21, 334-362.

Thornton, I. M., de’Sperati, C., \& Kristjánsson, Á. (2019). The influence of selection modality, display dynamics and error feedback on patterns of human foraging. Visual Cognition, 27(5-8), 626-648.

Treisman, A., Sykes, M., \& Gelade, G. (1977). Attention and Performance IV. Earlbaum, Hillsdale, 333-361. 
Trick, L. M. \& Enns, J. T. (1998). Lifespan changes in attention: The visual search task. Cognitive Development, 13, 369-386.

Vickers, D., Bovet, P., Lee, M. D., \& Hughes, P. (2003). The perception of minimal structures: Performance on open and closed versions of visually presented Euclidean travelling salesperson problems. Perception, 32(7), 871-886.

Warren, M., Moore, J. M., \& Vogtle, L. K. (2008). Search performance of healthy adults on cancellation tests. American Journal of Occupational Therapy, 62(5), 588-594.

Wiener, J. M., Ehbauer, N. N., \& Mallot, H. A. (2006). Path planning and optimization in the traveling salesman problem: Nearest neighbour vs. region-based strategies. In Dagstuhl Seminar Proceedings. Schloss Dagstuhl-Leibniz-Zentrum für Informatik.

Wolfe, J. M. (2010). Visual search. Current Biology, 20(8), 346-349.

Wolfe, J. M. (2013). When is it time to move to the next raspberry bush? Foraging rules in human visual search. Journal of Vision, 13(3), 10-10.

Wolfe, J. M., Cain, M. S., \& Aizenman, A. M. (2019). Guidance and selection history in hybrid foraging visual search. Attention, Perception, \& Psychophysics, 81(3), 637653. 10.3758/s13414-018-01649-5.

Woods, A. J., Göksun, T., Chatterjee, A., Zelonis, S., Mehta, A., \& Smith, S. E. (2013). The development of organized visual search. Acta Psychologica, 143(2), 191-199.

Zhang, J., Gong, X., Fougnie, D., \& Wolfe, J. M. (2017). How humans react to changing rewards during visual foraging. Attention, Perception, \& Psychophysics, 79, 22992309. https://doi.org/10.3758/s13414-017-1411-9 